\title{
PYRAMIDAL NEURONS OF THE LANGUAGE AREAS
}

\author{
Usha Devi Keezhathil Bhargavi', Romi Sadanandan²
}

${ }^{1}$ Additional Professor, Department of Anatomy, Government Medical College, Trivandrum.

2Professor, Department of Anatomy, Government Medical College, Alappuzha.

ABSTRACT

\section{BACKGROUND}

Gross anatomical differences have been suggested as the basis of cerebral lateralisation.

The aim of this study was to search for any histological evidence that supported asymmetry.

Objective was to study the pyramidal neurons of layer 3 and layer 5 of area 45 and area 22 of both hemispheres with regards to cell size and cell packing density.

Settings - Medical College, Trivandrum and S A T Hospital, Trivandrum.

Design - Post-mortem study of brains from different age groups including foetal specimens - A cross sectional study.

\section{MATERIALS AND METHODS}

Sections for light microscopy were taken from areas 45 and 22 of left and right hemispheres. They were stained with haematoxylin and Eosin and other special stains. The cell size and cell packing density were measured. The observations were put to statistical tests.

\section{RESULTS}

The pyramidal cells of layer 3 and layer 5 of area 45 of the left hemisphere were observed to be larger than those on the right hemisphere. The pyramidal cell packing density was more or less the same on both sides, with a slight increase in the left area 45 than in the right area 45 , but these findings did not achieve statistical significance.

\section{CONCLUSION}

Considering the fact that one hemisphere is larger than the other and that the language areas are more extensive on one hemisphere, asymmetries in somal size, dendritic arborisations and interneurons may be factors that contribute to the lateralisation of language. ${ }^{1}$

\section{KEYWORDS}

Brodmann's Area 45, Area 22, Outer Pyramidal Cell Layer, Inner Pyramidal Cell Layer, Asymmetry, Cerebral Dominance.

HOW TO CITE THIS ARTICLE: Bhargavi UDK, Sadanandan R. Pyramidal neurons of the language areas. J. Evolution Med. Dent. Sci. 2016;5(92):6846-6850, DOI: 10.14260/jemds/2016/1548

\section{BACKGROUND}

The age of earth is estimated to be approximately 4600 million years. Man began to speak only during the Pleistocene period, that is the time when he started using tools. It is thus clear that the faculty of language is phylogenetically a recent achievement. It has undergone several evolutionary processes along with man's social and cultural renaissance.

Language functions are lateralised to one hemisphere than the other. The dominant hemisphere is concerned with categorisation and symbolisation. The other hemisphere is specialised in the area of spatio-temporal relations. Dominance is the superior capacity of each side of the brain to acquire particular skills, for example, the left hemisphere is more involved in language functions, mathematical skills and analytical thinking whereas the right hemisphere is mostly nonverbal and prevails for emotion and holistic thinking.

Financial or Other, Competing Interest: None.

Submission 12-10-2016, Peer Review 05-11-2016,

Acceptance 11-11-2016, Published 17-11-2016.

Corresponding Author:

Dr. Usha Devi Keezhathil Bhargavi,

Additional Professor,

Department of Anatomy,

Government Medical College,

Trivandrum.

E-mail: ushakbdevi1@gmail.com

DOI: $10.14260 /$ jemds $/ 2016 / 1548$

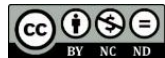

Many studies have been conducted to explain left hemisphere specialisation for language. Gross anatomical difference between the right and left hemispheres is suggested as the basis of cerebral dominance for language. The present work is a light microscopic study to look for any difference in the pyramidal cells of Broca's and Wernicke's area of both sides that will provide histological evidence for asymmetry.

\section{MATERIALS AND METHODS}

The study was conducted on 12 post-mortem brain specimens of different age groups ranging from 12-80 years. They were obtained from the mortuary of Medical College, Trivandrum. Brains where both sides were not intact, specimens from cases with congenital anomalies, infections and instances where handedness was not known were excluded from the study. The meninges were removed and sections for light microscopy were taken from the area between the anterior horizontal and anterior ascending rami of the lateral sulcus and from the posterior part of the superior temporal gyrus of both hemispheres. The cuts were perpendicular to the gyrus. The tissue bits were immediately transferred to labelled bottles containing $10 \%$ formalin as fixative. Later, these bits were dehydrated with graded strengths of alcohol, cleared and paraffin blocks prepared. Tissue blocks were cut at $5 \mu$ and $10 \mu$ thickness. A minimum of 50 sections were taken from a single block. The sections were stained with haematoxylin and Eosin and with special stains like Bielschowsky.

Specimens of foetuses, five in number of age 12 weeks to 20 weeks were collected from SAT Hospital, Trivandrum. The 
foetal specimens were fixed by immersing them in $10 \%$ formalin. Before immersion, the cranial cavity was exposed by a cruciate incision on the scalp and extending it carefully deeper till the brain matter with meninges was visible. This permitted the entry of formalin into the semisolid brain mass. Once the specimens were fixed, foetal brains were delicately dissected out. Sections for histological sections were taken from the presumptive motor and sensory language areas. These slides were also stained with H\&E and special stains.

\section{Special Stain}

Bielschowsky's Stain- The stain constitutes of silver nitrate, sodium hydroxide, ammoniacal silver, formalin, Gold chloride and sodium thiosulfate solution. The staining procedure was as follows:

The sections were deparaffinised and hydrated with distilled water and kept in $2 \%$ silver nitrate solution for 48 hours in the dark. They were then rinsed quickly in double distilled water. Ammoniacal silver solution was added to the section for 10-20 minutes or until section turned deep brown. Then the sections were rinsed in distilled water and reduced in $20 \%$ formalin for 5 minutes. They were then rinsed thoroughly in distilled water and toned in gold chloride solution for an hour. Sections appeared reddish violet. They were subsequently rinsed in distilled water and sodium thiosulfate solution was added to it for 1 minute. They were then washed in tap water and dehydrated with absolute alcohol and cleared in xylene and mounted with DPX. The axis cylinders and dendrites turned black against a purplish background.

The following properties of the stained sections were studied:

- Pyramidal neuron dimensions.

- $\quad$ Pyramidal cell packing density in high power field.

Determination of Pyramidal Neuron Dimension
Eye piece micrometre was standardised to a stage micrometre. The standardising index was found out to be 3.3. Hence, the cell dimension is $\mathrm{X} \times 3.3$, where $\mathrm{X}$ is the average of lengths of the cells, as observed through the eyepiece. The values were tabulated and then compared statistically.

\section{OBSERVATIONS AND RESULTS}

The grey matter and white matter, their changes with age, the number of pyramidal cells per high power field in the different layers of cortex, the pyramidal neuronal dimensions and their processes were examined. The pyramidal cell packing density (CPD) and pyramidal cell dimensions of layer 3 and layer 5 were compared with corresponding areas of the opposite hemisphere (table 1). Similarly, the CPD and cell size of area 45 and are 22 were compared. The results were analysed statistically and the significance was noted (1a).

In the present study, majority of specimens showed larger neurons in layer 3 and layer 5 in the layer 45 , but statistical significance was not reached.

Cell packing density in the area 45 of the left was more or less similar to the right with the left side showing a slight increase. The cell packing density did not vary in relation to the age.

Study of foetal specimens showed that below sixteen weeks of intrauterine life, the neuroblasts and glioblasts were all seen together without any layering pattern. Specimens above 16 weeks of gestation showed remarkable increase in the thickness of cortex. Layers had started to form (Image 2). The deeper cells showed linear row like arrangement. Cell dimensions were about 3.3 microns. The layering pattern became more clear in the sections above 20 weeks of gestational age (Image 3 ). The cell processes were also seen therein.

\begin{tabular}{|c|c|c|c|c|c|c|c|}
\hline \multirow{2}{*}{ Sub } & \multicolumn{4}{|c|}{ Cell Dimensions in Microns In Layer 3} & \multirow[b]{2}{*}{ Age } & \multirow[b]{2}{*}{ Sex } & \multirow[b]{2}{*}{ Hand } \\
\hline & $\mathbf{L B r}$ & LW & $\mathbf{R B r}$ & RW & & & \\
\hline A & 15.26 & 14.85 & 14.85 & 14.85 & 12 & M & $\mathrm{R}$ \\
\hline B & 15.67 & 15.68 & 13.5 & 14.85 & 20 & M & $\mathrm{R}$ \\
\hline $\mathrm{C}$ & 15.24 & 12.64 & 15.24 & 11.55 & 30 & $\mathrm{~F}$ & $\mathrm{R}$ \\
\hline $\mathrm{D}$ & 14.02 & 14.02 & 13.2 & 13.2 & 26 & $\mathrm{~F}$ & $\mathrm{R}$ \\
\hline $\mathrm{E}$ & 17.04 & 14.85 & 14.85 & 14.85 & 22 & $\mathrm{M}$ & $\mathrm{R}$ \\
\hline $\mathrm{F}$ & 15.26 & 14.85 & 14.85 & 14.85 & 18 & $\mathrm{M}$ & $\mathrm{R}$ \\
\hline G & 14.03 & 15.39 & 14.02 & 15.39 & 39 & $\mathrm{M}$ & $\mathrm{R}$ \\
\hline $\mathrm{H}$ & 17.33 & 14.85 & 17.33 & 14.85 & 35 & $\mathrm{M}$ & $\mathrm{R}$ \\
\hline I & 14.03 & 14.85 & 13.2 & 14.85 & 50 & $\mathrm{~F}$ & $\mathrm{R}$ \\
\hline $\mathrm{J}$ & 14.85 & 14.85 & 14.85 & 14.85 & 58 & $\mathrm{M}$ & $\mathrm{R}$ \\
\hline K & 14.03 & 14.85 & 13.2 & 14.85 & 45 & $\mathrm{M}$ & $\mathrm{R}$ \\
\hline $\mathrm{L}$ & 14.85 & 15.68 & 14.85 & 16.5 & 80 & $\mathrm{M}$ & $\mathrm{R}$ \\
\hline \multicolumn{8}{|c|}{ Table 1a } \\
\hline
\end{tabular}

\begin{tabular}{|c|c|c|c|c|c|c|c|}
\hline \multirow{2}{*}{ Sub } & \multicolumn{4}{|c|}{ Cell Dimensions in Microns In Layer 5} & \multirow[b]{2}{*}{ Age } & \multirow[b]{2}{*}{ Sex } & \multirow[b]{2}{*}{ Hand } \\
\hline & LBr & LW & RBr & RW & & & \\
\hline $\mathrm{A}$ & 16.17 & 16.5 & 15.51 & 17.59 & 12 & $\mathrm{M}$ & $\mathrm{R}$ \\
\hline $\mathrm{B}$ & 16.5 & 15.68 & 16.5 & 17.49 & 20 & $\mathrm{M}$ & $\mathrm{R}$ \\
\hline $\mathrm{C}$ & 16.5 & 15.84 & 17.32 & 12.37 & 30 & $\mathrm{~F}$ & $\mathrm{R}$ \\
\hline $\mathrm{D}$ & 15.26 & 14.02 & 14.03 & 14.02 & 26 & $\mathrm{~F}$ & $\mathrm{R}$ \\
\hline E & 17.04 & 18.15 & 16.5 & 18.15 & 22 & $\mathrm{M}$ & $\mathrm{R}$ \\
\hline $\mathrm{F}$ & 16.5 & 15.51 & 15.51 & 15.51 & 18 & $\mathrm{M}$ & $\mathrm{R}$ \\
\hline$G$ & 17.05 & 18.15 & 17.05 & 18.15 & 39 & $\mathrm{M}$ & $\mathrm{R}$ \\
\hline $\mathrm{H}$ & 20.62 & 16.5 & 18.69 & 16.5 & 35 & $M$ & $\mathrm{R}$ \\
\hline I & 16.5 & 14.85 & 13.2 & 14.85 & 50 & $\mathrm{~F}$ & $\mathrm{R}$ \\
\hline $\mathrm{J}$ & 16.5 & 17.33 & 16.5 & 18.15 & 58 & $M$ & $\mathrm{R}$ \\
\hline $\mathrm{K}$ & 17.33 & 15.68 & 16.5 & 15.68 & 45 & $\mathrm{M}$ & $\mathrm{R}$ \\
\hline $\mathrm{L}$ & 18.15 & 18.15 & 16.5 & 16.5 & 80 & M & $\mathrm{R}$ \\
\hline
\end{tabular}




\begin{tabular}{|c|c|c|c|c|c|c|c|}
\hline \multirow{2}{*}{ SUB } & \multicolumn{7}{|c|}{ Cell Packing Density, Layer 3} \\
\hline & LBr & LW & RBr & RW & Age & Sex & Hand \\
\hline A & 19 & 17 & 19 & 17 & 12 & $\mathrm{M}$ & $\mathrm{R}$ \\
\hline B & 16 & 14 & 15 & 19 & 20 & $\mathrm{M}$ & $\mathrm{R}$ \\
\hline $\mathrm{C}$ & 18 & 17 & 17 & 18 & 30 & $\mathrm{~F}$ & $\mathrm{R}$ \\
\hline $\mathrm{D}$ & 19 & 14 & 18 & 15 & 26 & $\mathrm{~F}$ & $\mathrm{R}$ \\
\hline E & 18 & 15 & 18 & 15 & 22 & $\mathrm{M}$ & $\mathrm{R}$ \\
\hline $\mathrm{F}$ & 16 & 14 & 15 & 17 & 18 & M & $\mathrm{R}$ \\
\hline$G$ & 16 & 13 & 14 & 13 & 39 & M & $\mathrm{R}$ \\
\hline $\mathrm{H}$ & 16 & 12 & 16 & 12 & 35 & $\mathrm{M}$ & $\mathrm{R}$ \\
\hline I & 13 & 17 & 11 & 17 & 50 & $\mathrm{~F}$ & $\mathrm{R}$ \\
\hline $\mathrm{J}$ & 13 & 14 & 17 & 15 & 58 & $\mathrm{M}$ & $\mathrm{R}$ \\
\hline $\mathrm{K}$ & 16 & 16 & 16 & 15 & 45 & $M$ & $\mathrm{R}$ \\
\hline $\mathrm{L}$ & 18 & 17 & 17 & 17 & 80 & $\mathrm{M}$ & $\mathrm{R}$ \\
\hline \multicolumn{8}{|c|}{ Table $2 a$} \\
\hline
\end{tabular}

\begin{tabular}{|c|c|c|c|c|c|c|c|}
\hline & \multicolumn{7}{|c|}{ Cell Packing Density Layer 5 } \\
\hline SUB & LBr & LW & RBr & RW & Age & Sex & Hand \\
\hline A & 20 & 17 & 20 & 17 & 12 & $\mathrm{M}$ & $\mathrm{R}$ \\
\hline B & 17 & 15 & 18 & 15 & 20 & $\mathrm{M}$ & $\mathrm{R}$ \\
\hline C & 18 & 22 & 21 & 17 & 30 & $\mathrm{~F}$ & $\mathrm{R}$ \\
\hline $\mathrm{D}$ & 18 & 17 & 14 & 14 & 26 & $\mathrm{~F}$ & $\mathrm{R}$ \\
\hline E & 20 & 16 & 16 & 15 & 22 & $\mathrm{M}$ & $\mathrm{R}$ \\
\hline F & 17 & 14 & 16 & 16 & 18 & $\mathrm{M}$ & $\mathrm{R}$ \\
\hline $\mathrm{G}$ & 16 & 13 & 13 & 13 & 39 & $\mathrm{M}$ & $\mathrm{R}$ \\
\hline H & 16 & 9 & 15 & 9 & 35 & $\mathrm{M}$ & $\mathrm{R}$ \\
\hline $\mathrm{I}$ & 10 & 13 & 10 & 13 & 50 & $\mathrm{~F}$ & $\mathrm{R}$ \\
\hline $\mathrm{J}$ & 12 & 14 & 14 & 14 & 58 & $\mathrm{M}$ & $\mathrm{R}$ \\
\hline K & 14 & 16 & 13 & 17 & 45 & $\mathrm{M}$ & $\mathrm{R}$ \\
\hline $\mathrm{L}$ & 16 & 15 & 16 & 14 & 80 & $\mathrm{M}$ & $\mathrm{R}$ \\
\hline
\end{tabular}

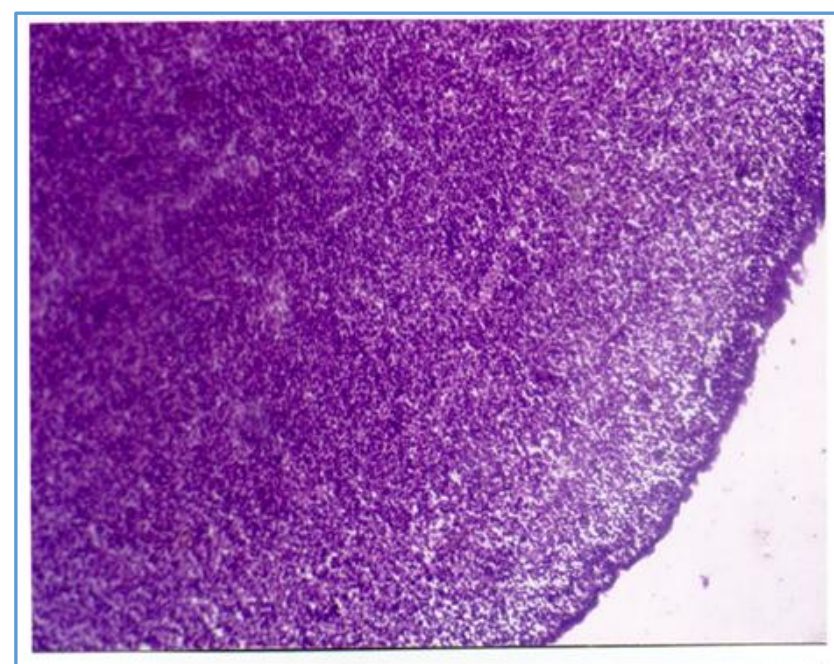

Section showing microscopic structure of foetal brain 12-16 weeks gestation ( $x 10$ magnification $\mathrm{H} \& \mathrm{E}$ stain).

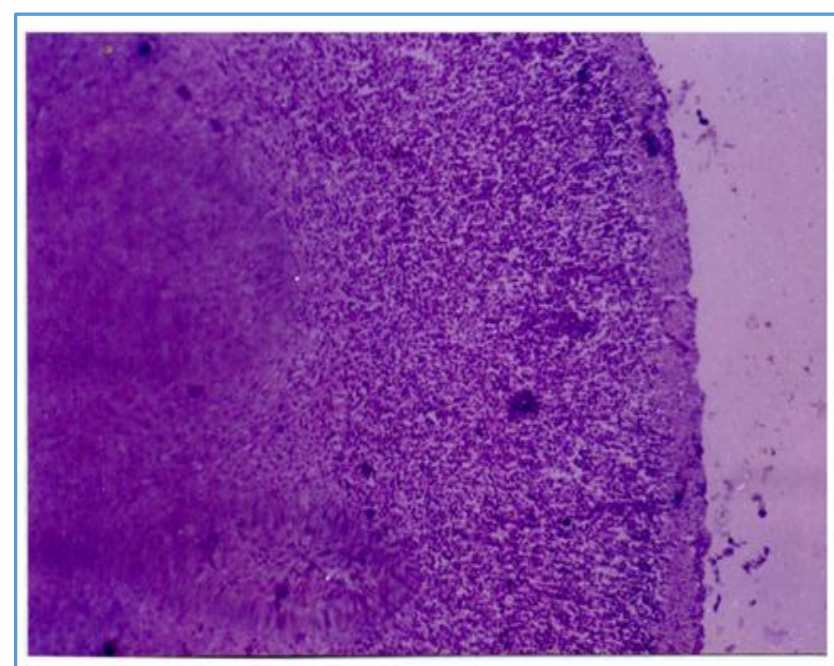

Section showing microscopic structure of foetal brain $16-18$ weeks gestation (x 10 magnification $\mathrm{H} \& \mathrm{E}$ stain).

Image 1

Image 2 


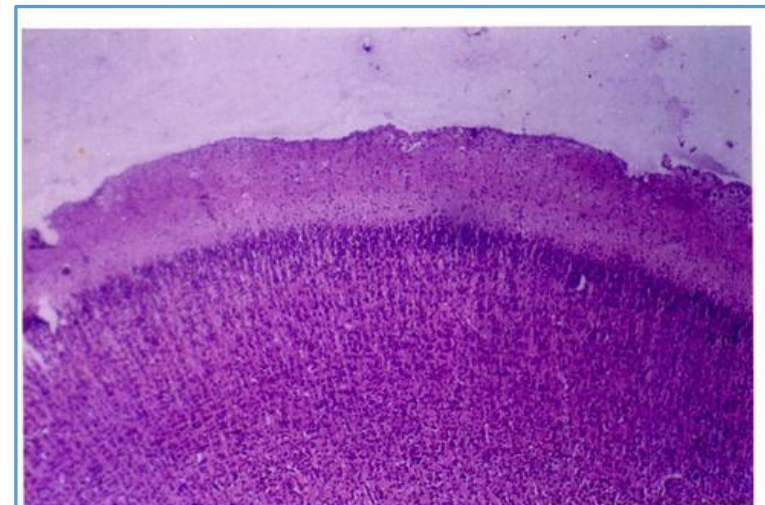

Section showing microscopic structure of foetal brain around 20 weeks gestation (x 10 magnification $\mathrm{H} \& \mathrm{E}$ stain).

\section{Image 3}

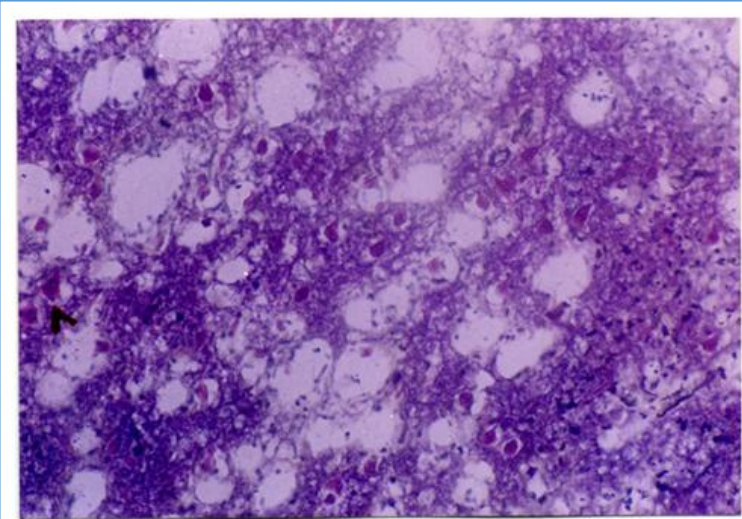

Section showing microscopic structure of brain of 20 year old male ( $x$ 60 magnification Bielschowsky's stain) $>$ pyramidal neurons.

\section{Image 4}

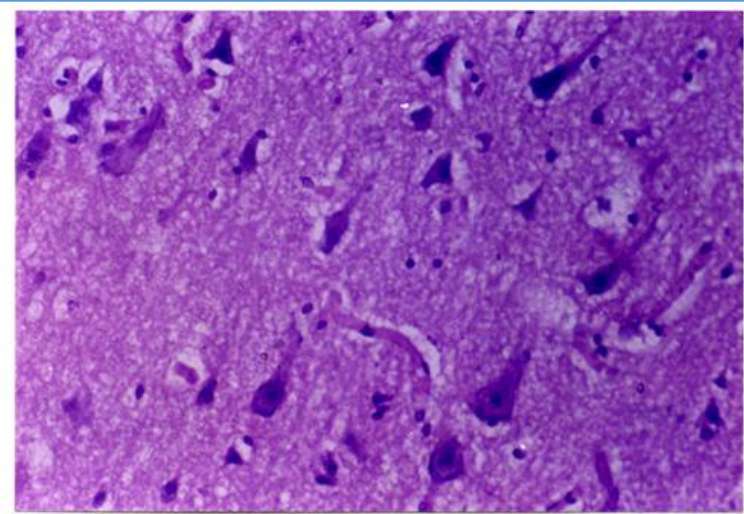

Section showing microscopic structure of left area 45 of male 22 years large pyramidal neurons in layer V (x 60 magnification).

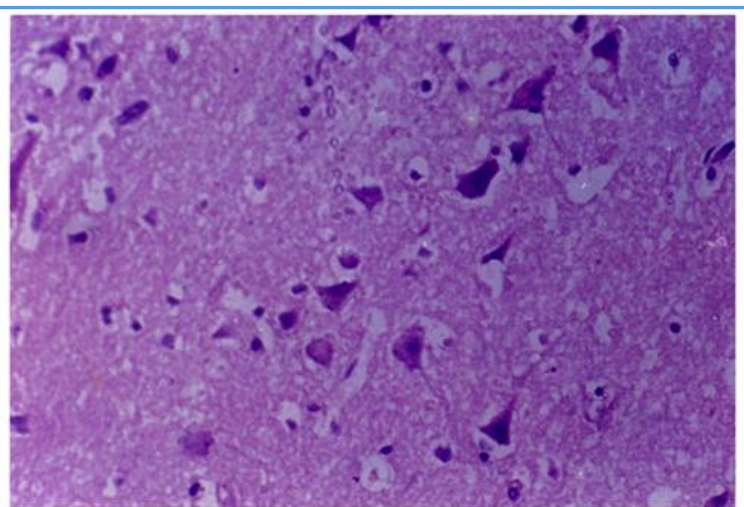

Section showing microscopic structure of right area 45 of male 39 years pyramidal neurons in layer V (x 60 magnification)

\section{Image 6}

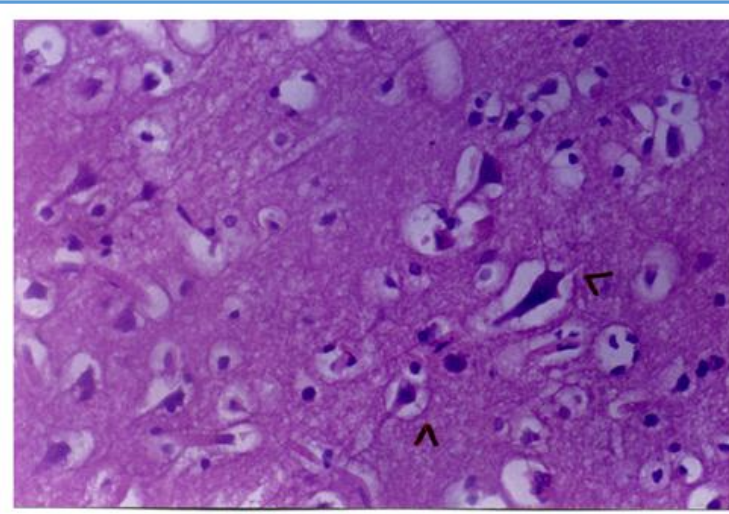

Section showing microscopic structure of left area 45 of male 39 years $>$ pyramidal neurons and processes in layer V (x 60 magnification).

Image 7

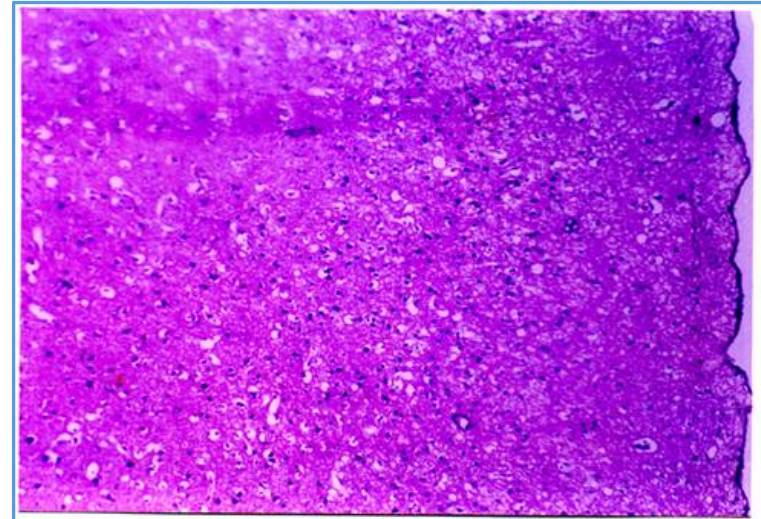

Section showing microscopic structure of posterior part of left superior temporal gyrus of male 58 years ( $x 10$ magnification $\mathrm{H} \& \mathrm{E}$ stain).

\section{Image 8}

\section{DISCUSSION}

Tamara et al have reported that there were significantly large pyramidal neurons on the left area 45 , but the mean size of the layer 3 pyramidal cells was not different in the left and right hemisphere. ${ }^{1}$

The findings of our study partially conformed to their work in that the mean size of layer 3 pyramidal cells were not significantly different in the left and right hemispheres. Even though majority of specimens in our study showed larger neurons in the layer 3 and layer 5 on the left, a statistical significance was not obtained.1,2 
There may be a population of large neurons in the left area 45 which contributes to functional lateralisation.

The dendritic parameters studied in certain works have revealed that there are hemispherical differences in their structure.3,4 It may be logical to assume that a greater somal size and dendritic arborisation may be involved in the dominance of certain faculties of brain. Ach-E rich magnopyramidal neurons seen in certain areas of the brain showed a left right size asymmetry.5,6 These cells may not be demonstrable with the staining technique used in this study. Asymmetry of cell packing density exists in certain parts of the cortex. ${ }^{7}$ Our observations are consistent with Uylings et al who stated that the neuronal numbers were more on left but were not significant. 8 In the present study, the number of neurons in the layer 3 and 5 were more in the left area 45, yet did not show significant difference. Overall neuronal density did not differ between groups. ${ }^{7}$ We disagree with the observation that the cells numbers decrease with age. ${ }^{9}$ There was no increase or decrease of neurons, in relation to age. Researchers have proposed that interhemispheric asymmetry exists in area 45 with a left larger than right asymmetry. But this cytoarchitecture continues to change throughout life as a result of microstructure plasticity. ${ }^{10}$ The left larger than right asymmetry in the volume fractions of cell bodies was reached at approximately five years in area 45 . In our foetal studies, we could not make out any differences in the cell dimensions or cell packing density between the left and right hemispheres substantiating the view that such changes occur later, as the child grows. An increase in grey matter density in Broca's area may be in response to intensive audio motor skill acquisition. ${ }^{11,12}$

The cell dimensions and the cell packing density of the area 22 were almost the same on both sides. The sections resembled agranular cortex.

Galaburda et al have opined that cortical asymmetry varies among individuals. ${ }^{13}$ The more asymmetric the region, the smaller the neurons and smaller the density of interhemispheric connections and greater the intrahemispheric connections. There are qualitative and quantitative differences in the connectivity of the larger side of an asymmetrical region. ${ }^{14}$

Considering the fact that one hemisphere is larger than the other and that the language areas are more extensive on one hemisphere, asymmetries in the interneurons, somal size and dendritic arborisations may be factors that contribute to the lateralisation of language. $1,3,15,16,17$ As the study included only right handers, an exact evaluation of the functional asymmetry of speech could not be ascertained. However, a relatively large sample size and inclusion of brains of left handers may provide better resolution.

The degree of dominance for language functions by one or other hemisphere may be a function of degree of asymmetry. These structural differences may help to explain the variability in degree of recovery from lesions that produce language deficits. Study of such neurons may throw light on the intrinsic circuitry of language processing. ${ }^{18}$

\section{REFERENCES}

1. Hayes TL, Lewis DA. Hemispheric differences in layer 3 pyramidal neurons of the anterior language area. Arch Neurol 1993;50(5):501-5.
2. Bogolepova IN. Vestn Ross Akad Med Nauk 2001;4:61-4.

3. Anderson B, Rutlege V. Dendritic trees of right hemisphere. Brain 1996;119(6):1983-90.

4. Hayes TL, Lewis DA. Magnopyramidal neurons in the anterior motor speech region. Dendritic features and interhemispheric comparisons. Arch Neurol 1996;53(12):1277-83.

5. Garcia RR, Montiel JF, Villalon AU, et al. AChE-rich magnopyramidal neurons have a left-right size asymmetry in Broca's area. Brain Res 2004;1026(2):31316.

6. Hutsler JJ. The specialised structure of human language cortex: pyramidal cell size asymmetries within auditory and language associated regions of temporal lobes. Brain Lang 2003;86(2):226-42.

7. Cullen TJ, Walker MA, Eastwood SL, et al. Anomalies of asymmetry of pyramidal cell density and structure in dorso lateral pre frontal cortex in schizophrenia. Br J Psychiatry 2006;188:26-31.

8. Uylings HB, Jacobsen AM, Zilles $\mathrm{K}$, et al. Left right asymmetry in volume and number of neurons in adult Broca's area. Cortex 2006;42(4):652-8.

9. Brodal A. Neurological anatomy in relation to clinical medicine. $2^{\text {nd }}$ edn. New York: Oxford University Press 1981.

10. Amunts K, Schleicher A, Ditterich A, et al. Broca's region: cytoarchitectonic asymmetry and developmental changes. J Comp Neurol 2003;465(1):72-89.

11. Sluming V, Barrick T, Howard $M$, et al. Voxel-based morphometry reveals increased gray matter density in Broca's area in male symphony orchestra musicians. Neuroimage 2002;17(3):1613-22.

12. Abdul- Kareem IA, Stancak A, Parkes LM, et al. Increased grey matter volume of left pars opercularis in male orchestral musicians correlate positively with years of musical performance. J Magn Reson Imaging 2011;33(1):24-32.

13. Galaburda AM, Rosen GD, Sherman GF. Individual variability in cortical organization: its relationship to brain laterality and implications to function. Neuropsychologia 1990;28(6):529-46.

14. Rosen GD, Sherman GF, Galaburda AM. Neuronal subtypes and anatomic asymmetry: changes in neuronal number and cell packing density. Neuroscience 1993;56(4):83339.

15. Carne RP, Vogrin S, Litewka L, et al. The cerebral cortex: an MRI-based study of volume and variance with age and sex. J Clin Neurosci 2006;13(1):60-72.

16. Sherwood CC, Wahl E, Erwin JM, et al. Histological asymmetries of primary motor cortex predict handedness in Chimpanzees (Pan troglodytes). J Comp Neurol 2007;503(4):525-37.

17. Moffat SD, Hampson E, Lee DH, Morphology of the planum temporal and corpus callosum in left handers with evidence of left and right hemisphere speech representation. Brain 1998;121(Pt 12):2369-79.

18. Galaburda AM, Sanides F, Geschwind N, et al. Human brain. Cytoarchitectonic left - right asymmetries in the temporal speech region. Arch Neurol 1978;35(12):812-7. 